\title{
Research on the Applications of Information Technology and CAD based Costume Design Method for College Clothing Major Education
}

\author{
Jiarong $\operatorname{Han}^{1}$ \\ ${ }^{1}$ Northeast Dianli University ,Jilin , Jilin 132012 China
}

\begin{abstract}
In this paper, we research on the applications of information technology and CAD based costume design method for college clothing major education. Information technology and curriculum integration, not only is to use information technology. Some tools used in the clothing CAD system diversity, complex operation, the teacher hands the nuances of the mouse operation, such as strike left or right students is difficult to see. Our proposed method promote the interaction of the teachers and the students which will be effective for enhancing the class performance.
\end{abstract}

Keywords: Information Technology; Costume Design; College Clothing Major; Education Reform.

\section{Introduction}

With the progress of science and technology and with computer and Internet technology as the core of information technology is penetrating into more and more industry. Information has become an important symbol of modernization of education. Clothing specialized teaching multifarious, practical and high technical characteristics of the traditional teaching has always been a challenge with the rapid development of garment industry is an urgent need to cultivate autonomous creative talents. However, specialized senior applied and inter-disciplinary talent shortage phenomenon has seriously affects the sustainable development of the apparel industry to train talents for quick which must be vigorously the introduction of information technology. Information technology and curriculum integration, not only is to use information technology. More in need of renewal education idea, guided by the modern education teaching view, technology, methods, resources, and secondary vocational clothing specialized courses in organic unity. However, there are some existing challenges that need to be solved. (1) Understanding fuzzy integration concept. Many people think. Demand for campus network. As a modern campus construction is computer courses are offered to students. But in order to guarantee the teaching schedule. General course teaching is not necessarily need to adopt modern information technology. (2) Emotional communication lack between teachers and students. Fundamental change has happened in the traditional classroom teaching mode. Some teachers and students appeared not appreciate. But there is no update on teaching idea. Teachers are still around the classroom, the students' main body roles reflect not to come out. But heavy activity form for the effect of activity. (3) A lack of high-technique teaching resources. Due to the application of information technology in secondary vocational clothing specialized teaching is still in the early stage of development. For reference and use of multimedia teaching resources are relatively small, and there exists a subject distribution is not balanced, single kinds, high quality resources and so on which is difficult to meet the diversified demand of teachers and students [1-2].

CAD technology application in the field of fashion design has a long history and some commercial clothing CAD system with considerable practicability, user friendly and the characteristics of the commercialization has wide 
application in the clothing industry. Clothing CAD system of computer aided garment design system, is a comprehensive collection of computer graphics, database, network communications and other fields such as computer knowledge in the integration of modern high-tech, used to implement product development and engineering design. Because the computer has quick computing speed, information storage capacity big, memory capacity, high reliability which can quickly reflect the characteristics of graphic images, designer that can be modified by computer to develop, analyze, design of his works. In the actual teaching process, and always runs through based on the theory of clothing professional knowledge, the combination of demonstration and guidance. Some tools used in the clothing CAD system diversity, complex operation, the teacher hands the nuances of the mouse operation, such as strike left or right students is difficult to see, this is required in addition to the use of multimedia in the teaching process, blackboard and physical demonstrations outside, still need one-on-one tutoring. Because the student used a computer directly into actual combat, rather than the use of step-by-step which is boring to study tools [3-4].

To deal with the mentioned drawbacks and issues, in this paper, we research on the applications of information technology and CAD based costume design method for college clothing major education. Using modern information technology curriculum integration which should absorb the advantages of all kinds of teaching modes will be meaningful. New information technology does not weaken the teachers' position but we have to admit. The development of new technology greatly changed the role of the teacher. The teacher must adapt to the new technology brings the new requirements of information technology provides the new mode of teaching and learning conditions possible. In the following sections, we will illustrate the mentioned issues in detail.

\section{The Proposed Approach and Methodology}

The Principles of College Clothing Major Education. Education teaching reform is the key to the reform of the talent training scheme, the talent training scheme including training objectives, training specifications and training modes. Training mode determines the institutions of higher learning delivery of the basic features of the excellent talents to the society. The reform of the talent training scheme and optimization of the professional curriculum system structure adjustment is urgently needed. Curriculum system in under the guidance of the training objectives based on the related subject knowledge and ability requirements according to certain proportion and the logical relationship between choice and organization of curriculum structure, curriculum content system of education and teaching activities. Clothing design and engineering specialty course system of characteristic is the clothing product design theory, method and clothing production technology management organically, engaged in garment production and practice for the students lays the broad and solid foundation. Clothing design and engineering specialty course system optimization is the premise of effective analysis and evaluation of the curriculum system.

The rapid development of modern information technology makes the apparel industry grows, clothing specialized teaching methods and means in traditional education, backward means, because of the small imparting information visual were some factors, ductility teaching activities is difficult to vivid, teaching effect is limited, far cannot satisfy the new age students to learn knowledge, learning desire of obtaining information. Project teaching is a kind of enterprise product design and development, production management and operation, pay attention to in the teaching process relative to meet the practical work of teaching content and teaching method. Such a teaching mode is a professional course teaching and the process of enterprise project need, according to the 
requirements of enterprise post should have the ability to work continuously, the overall design to teaching, organize the teaching contents and adjust teaching form and teaching method. The traditional education pattern and step is shown in the following. (1) Specific project objectives. To make the students be familiar with product development or manufacturing process, control the requirements of product design and product production link of technical standard, thus improve the practice ability. (2) Determine the project teaching task. Combined with the enterprise product research and related development projects, course analysis, determine the teaching task. Students are required to have mastered professional knowledge, group cooperation in order to complete the project research and development tasks independently. (3) The development of project teaching plan. Project director discussed by teachers and enterprise and determine the project process and implementation plan. (4) Project teaching group. (5) Solve the problem of project teaching. In the process of implementation, to fulfill the task of each stage to record down, the problem of analyzing the cause of the problems which puts forward the method to solve the problem. (6) Report to complete the project teaching. Members of the group, according to the division of task to write a report, the process of such as have mastered what knowledge, which link problems, in the later in the learning process should be how to learn, such as by head after finishing, form a complete training report.

The Novel CAD based Costume Design Method. On teaching software used by choice, in the face of the clothing CAD software types of diversification in recent years, the first to compare various clothing CAD system software at home and abroad. Due to the vocational school clothing $\mathrm{CAD}$ teaching using multimedia demonstration teaching, by students, students and teachers with the computer interaction, complete the transformation of theory and practice, promote each other. So choose the most suitable and practical needs of the situation of the school teaching material to make the training of students' quality to achieve the requirement of the enterprise such jobs. Have made design pieces structure base system. According to the paper structure and human body size to generate the corresponding sample piece base figure. Figure is modified according to the design requirements of garment piece sample. Of the polish modified sample figure for grading processing, generate pieces of row material, generating paper discharging figure, calculate the utilization rate of fabric; About the implement drawing output will be generated; To meet the functional requirements, the establishment of corresponding database, graphics library and library management system. Clothing CAD course content involves the computer application technology, clothing design, clothing, and other professional fields, the above cross each other more specialized courses, interdependent characteristics require according to the characteristics of students in teaching design, carefully selected materials and class practice mainly by means of computer operation make the theory and the practice operation complement each other. In the figure one, we show the sample of the CAD based fashion design and simulation result. 


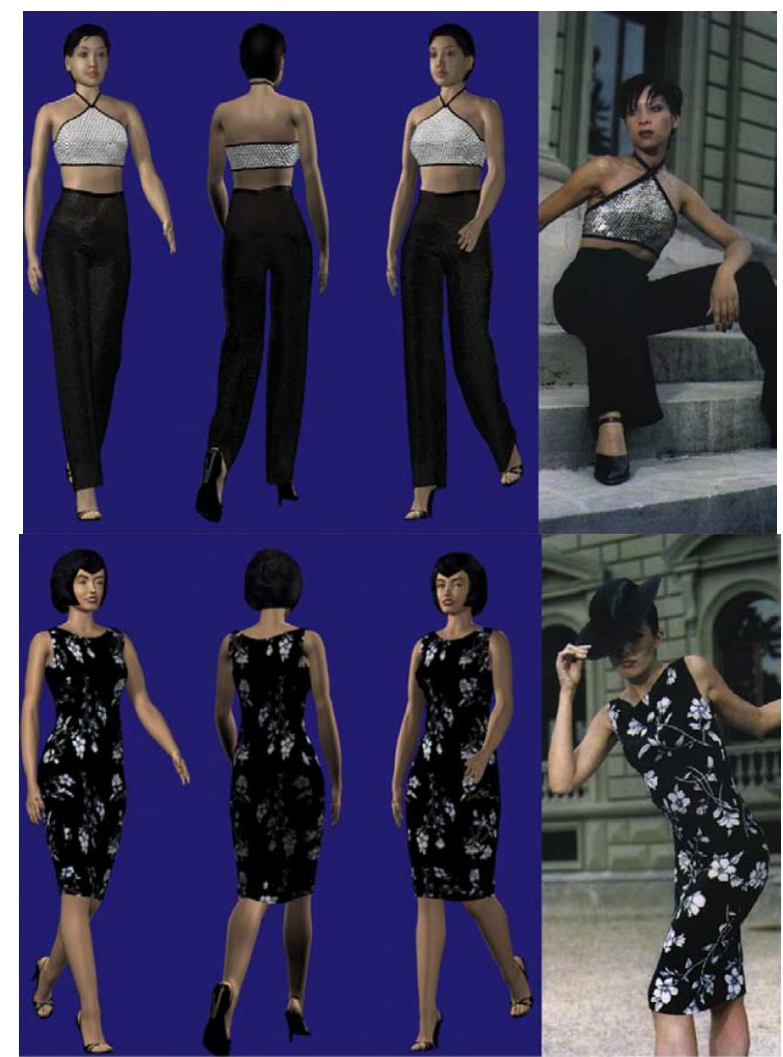

Figure 1. The Sample of the CAD based Fashion Design and Simulation Result

Friendly interface, easy to operate clothing CAD multimedia teaching courseware, is the student classroom learning and after-school practice good teachers and wise friends. The application of the courseware, greatly improving the teaching efficiency, easing the burden on the teachers' teaching, arouse the students' interest in learning, has obtained the good teaching effect. What to teach basic tool to introduce the software function and usage. As a result of the limitation of class, the teacher can only be selectively with clothes introduces common functionality, but it is not possible to all functions of the software system in detail, and students' learning is always in a passive to accept the position. Clothing CAD course of hardware facilities, is the foundation of the clothing CAD teaching reform and the important guarantee. Hardware facilities include multimedia teaching facilities and students practice room, the computer network learning platform and clothing CAD auxiliary equipment. In recent years, the school, college, increased investment in hardware, to ensure the clothing CAD curriculum reform smoothly, promote effectively. Such as introduction and configured a large-format digitizer, plotter, scanners, high-resolution color printer, digital camera, projector, print sample cutting machine, 3D human body measurement instrument and other advanced equipment, at the same time, established the clothing CAD lab. Due course is a course of many cross clothing CAD, the content involved in computer application technology, costume design, clothing and other professional fields, based on computer application, costume design, clothing structural design, apparel industry pattern design and clothing production management theoretical basis for a comprehensive course, so through the course of reform and construction, improve the students' learning interest and efficiency. In the figure two, we show the user interface of our designed CAD system 


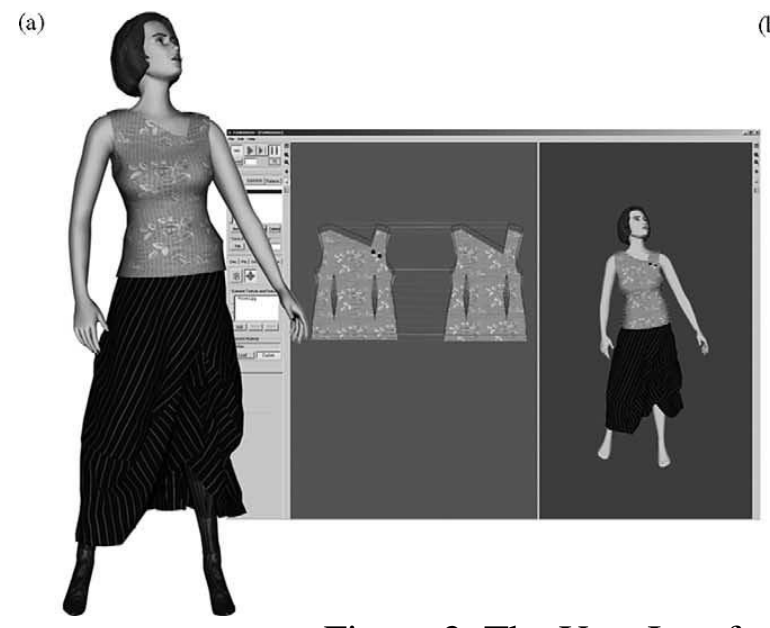

(b)

Figure 2. The User Interface of the Designed System

The Effect of the CAD based Design Methodology. Based on static 3D garment design from design to production reality visualization technology and visualization and animation technology we could obtain the acceptable result. The close relationship between the style of the clothes and the selected fabric which means that the fabric display form is loading clothing 'meter system is an important link of special foot clothing material performance of model design and appearance modelling has a significant impact. Due to the anisotropy of textile materials and the difficulty of deformation simulation, fabric deformation model is very complex. Through our design system, the performance of the education and design will be better.

\section{Conclusion}

In this paper, we research on the applications of information technology and CAD based costume design method for college clothing major education. Early of the clothing CAD system is limited to two-dimensional plane, use computer to make the garment grading, layout, style design, pattern design, etc. With the rapid development of computer technology and the popularity of Internet network, using computer to film and television creation, game development and more and more popular, virtual reality and the realistic simulation and clothing of clothing character animation simulation is widely used in these areas. The development of new technology greatly changed the role of the teacher. The teacher must adapt to the new technology brings the new requirements of information technology provides the new mode of teaching and learning conditions possible. Our method solves the issues well which is simulated with numerical analysis.

\section{References}

[1] Kang Y, Kim B C, Mun D, et al. Method to simplify ship outfitting and offshore plant equipment three-dimensional (3-D) computer-aided design (CAD) data for construction of an equipment catalog[J]. Journal of Marine Science \& Technology, 2014, 19(2):185-196.

[2] Zhang, S. H., Yang, C. Y., \& Hai-Bo, H. E. (2014). The application of design navigation based on features and parameterization in piston design. Modular Machine Tool \& Automatic Manufacturing.

[3] Liang Y, Chen W, Sun Y, et al. A mechanical structure-based design method and its implementation on a fly-cutting machine tool design[J]. International 
Journal of Advanced Manufacturing Technology, 2014, 70(9-12):1915-1921.

[4] Xing Y, Li J, Huang X. Information Transformation between CAD and XNA
Based on XML[J]. China Mechanical Engineering, 2014. 